\title{
SEABUCKTHORN OR HIPPOPHAE RHAMNOIDES WINTER TWIGS EXTRACTS COULD IGHTEN SKIN PIGMENTATION
}

\section{Meybeck Alain}

AM Phyto-Conseil, Courbevoie, France, e-mail: ameybeck@club-internet.fr

Although Seabuckthorn fruit or seed oils, and fruit extracts are used in cosmetics formulations as emollients and antioxidants, the potential of branch extracts had not yet been examined. The present study showed that Hippophae rhamnoides winter twigs extracts have the highly valuable property to inhibit pigment formation in skin cells, whereas an extract of twigs collected in summer and bearing leaves had practically no effect. Young Seabuckthorn branch extremities and shoots were harvested in winter (February or april) or summer (early September) in The Netherlands coastal dunes, particularly taking care not to collect too much woody material. After freeze drying, the twigs were ground to a powder which was extracted overnight either with methanol, $70 \%$ ethanol-water, or water. The dry extracts were then partitioned between water and butanol, and the fractions were characterized by HPLC and TLC. The different fractions were thereafter submitted to special tests on cultures of melanocytes (skin cells producing pigment) which allow to evaluate the amount of melanin pigment synthesized. These tests have shown that:

- seabuckthorn winter twigs polar extracts inhibit the biosynthesis of melanin pigments by skin cells;

- a seabuckthorn summer twig extract has practically no activity on melanogenesis;

- the active compounds responsible for the whitening effect of Hippophae rhamnoides winter twig extracts are water soluble molecules;

- these active molecules seem to be indole derivatives.

Therefore, Hippophae rhamnoides winter twigs extracts could be developed for brightening or whitening cosmetic formulations (Patent Application filed on February 28, 2011). This new utilization of Seabuckthorn is bound to further increase its economic importance by providing an industrial exploitation during the winter season.

\section{A NEW METHOXY FLAVONOID GLYCOSIDE FROM ADENANTHERA PAVONINA LEAVES}

\author{
(C) Mohammed R. S. ${ }^{1}$, Abou Zeid A. H. ${ }^{1}$, El-Kashoury E. A. ${ }^{2}$, Sleem A. A. ${ }^{3}$, Waly D.A. ${ }^{1}$ \\ ${ }^{1}$ Pharmacognosy Dept., National Research Center, Cairo, Egypt \\ ${ }^{2}$ Pharmacognosy Dept., Faculty of Pharmacy, Cairo University, Kasr Al-Aini, 11562, Cairo, Egypt \\ ${ }^{3}$ Pharmacology Dept., National Research Centre, El-Tahrir St., Dokki, 12622, Cairo, Egypt
}

Adenanthera pavonina is a plant belonging to family Fabaceae, used in Indian folk medicine against rheumatism, gout, to treat dysentery, diarrhoea and tonsillitis. Aim of the work was the screening of in vivo antioxidant (1) and in vitro anticancer (2) activities of total ethanol and sucessive extracts of the plant and isolation of its compounds. Dried powdered leaves of the plants was successively extracted with solvents of increasing polarities (pet. ether, chloroform, ethyl acetate, methanol and total ethanol). Fractionation of successive methanol extract was done on polyamide column and purification of the isolated compounds was done on sephadex LH20. Antioxidant activity of total ethanol and successive extracts were performed. Cytotoxic activity of total ethanol and compound (I) and (II) were screened against four human cancer cell lines (HEPG-2, MCF-7, HELA and HEP-2). A new methoxy flavanol glycoside named as quercetin 3-O- $\alpha$-dirhamnopyranosyl- ( 1 '.$\left.2{ }^{\prime \prime}, 1^{\cdots \cdots}-6^{\prime \prime}\right)-\beta$-glucopyranoside-4'-methoxy (I) as well as kaempferol-3-O- $\alpha$-dirhamnopyranosyl- $\left(1^{\cdots}-2{ }^{\prime \prime}, 1^{\cdots}\right.$ 6 “')- $\beta$-glucopyranoside (II) isovitexin (III) quercetin3-
-O-rhamnopyranosyl (1'“-4") $-\beta$-glucopyranoside (IV) quercetin-3-O- $\beta$-glucopyrano side (V) quercetin3-O-rhamnopyranosyl $\quad\left(1^{\cdots}{ }^{\cdots}-2^{\prime}\right)$ - $\beta$-glucopyranoside (VI) kaempferol-3-O- $\alpha$-rham-nopyranosyl (1'.-2“)- $\beta$ glucopyranoside (VII) quercetin-3-O-rhamnopyranosyl ( $1^{\cdots}$-2 $\left.{ }^{\prime \prime}\right)$ - $\beta$-glucopyranoside (VIII) kaempferol (IX) and quercetin $(\mathrm{X})$. Structures of the isolated compounds were established by spectroscopy (UV, ${ }^{1} \mathrm{H},{ }^{13} \mathrm{C}$, and 2D). Total ethanol showed $49.3 \%$ of changeantioxidant activity compared with $65.4 \%$ of vitamin E. The total ethanol extract showed a significant cytotoxic activity against HEPG-2 $(\mathrm{IC} 50=2.50 \mu \mathrm{g})$ compared with Cisplatin (IC50>10 $\mu \mathrm{g})$.

References: (1) Beutler E., Duron O. and Kelly B. (1963). Improved Method for the Determination of Blood Glutathione. Journal of Laboratory and Clinical Medicine, 61: 882-888. (2).Skehan P., Storeng R., Scudiero D., Monks A., McMahon J., Vistica D., Warren J.T., Bokesch H., Kenney S. and Boyd M.R. (1990). New colourimetric cytotoxicity assay for anticancer drug screening. Journal of National Cancer Institute, 82: 1107-1112. 